\title{
Lenguas, literaturas y nacionalidades en Lituania (y en el Báltico oriental $)^{1}$
}

\author{
PIETRO U. DINI
}

\begin{abstract}
Languages, literatures and nationalities in Lithunia (and in the East Baltic region). This article's focus is on Lithuania and its literature, but many considerations contained in it are also valid for the whole East Baltic cultural region.

A preliminary distinction is made inside Lithuanian literature between Ortsgebundenheit and Sprachgebundenheit, in order to show and discuss the strong multilingualism which has characterized the Baltic region already in an early period. A short excursus follows, pointing out the possible importance the "national literary model" could have had in different epochs.

Similarities with the situation in Latvia and Estonia, but also with other central European countries, are stressed concerning the delay in building sovereign states; a parallel is drawn especially with Catalonia. The importance and the role played by the language in all these cases is underlined and commented on. Other considerations regard the literature in exile and the new literary tendencies that have emerged after the identity protest movement at the end of the 1980 s which led to the declaration(s) of independence.

Finally, general thoughts are expressed concerning the concept of "national literature" in the case of countries whose history has been characterized by an intermittence of sovereignty (the case of the Baltic countries), and for other longer-established European countries. The supporters of Weltliteratur normally completely neglect these aspects. In the author's mind, however, they also should be attentively considered.
\end{abstract}

Keywords: Lithuanian literature, Baltic literatures, Baltic-Catalan literary parallels, national literary model, national literature, Weltliteratur, literature and language

1 Versión adaptada de la ponencia Ultima Europae prouincia? Lingue, letterature, nazionalità in Lituania e nel Baltico orientale, presentada en el coloquio Letteratura e nazionalità: un'equivalenza in discussione, Turín, 23-24 de octubre de 2012 (cfr. Letteratura e nazionalità, edición a cargo de Franco Marenco, Bolonia, Il Mulino, 2014, pp. 195-220). Traducción del italiano de Albert Lázaro-Tinaut.

DOI: http://dx.doi.org/10.12697/IL.2015.20.1.5 


\section{A modo de introducción}

En un texto a propósito de la invasión rusa de Checoslovaquia en 1968, Milan Kundera (2008) decía:

Yo y mis amigos hemos vivido este episodio como una catástrofe sin esperanza. Y si no se tiene en cuenta nuestro estado de ánimo de entonces, no se puede entender nada... Los regímenes van y vienen. Pero las fronteras de la civilización permanecen. Nos vimos fagocitados por otra civilización. Otras muchas naciones, en el interior del Imperio ruso, estaban a punto de perder incluso su lengua y su identidad.

Este testimonio describe la que en otros lugares se denominó "el secuestro" (según algunos, "la pérdida") de la Europa del Centro (cf. Hoskoveć 2005; Bojtár 2006). Como es bien sabido, habría que esperar hasta principios de la década de 1990 para que aquella herida en el corazón del Viejo Continente empezara a cicatrizar y Europa recuperara la Europa del Centro...

Entre las "otras muchas naciones en el interior del Imperio ruso" a las que aludía Kundera, estaban sin duda los bálticos (mejor dicho, los bálticos orientales, si se prefiere una denominación geopolítica, ya que, como es sabido, lituanos y letones pertenecen a la familia lingüística indoeuropea y los estonios, en cambio, a la finoúgria). Lituania es una antigua entidad política de gran importancia en la Europa medieval y renacentista. Letonia y Estonia no aparecieron en la escena política hasta el siglo XX. Sin embargo, la historia de las tres naciones ha estado siempre vinculada por numerosos lazos comunes.

Recuérdese que fue precisamente la protesta identitaria de los bálticos orientales, a finales de la década de 1980, lo que dio el golpe de gracia a la Unión Soviética. Lo que no acabaron de entender los dirigentes del Kremlin (Gorbachov incluido) fue el problema nacional, que siempre ha estado estrechamente vinculado (y no solo para los bálticos del Báltico oriental) con el de la lengua. No es casual que en el fragmento del escritor checo reproducido al principio se ponga de relieve el binomio lengua-identidad: "Otras muchas naciones... estaban a punto de perder incluso su lengua y su identidad”. Y con ello, desde el punto de vista que pretendo ofrecer, nos encontramos plenamente in media re.

Para presentar mejor el caso de las comunidades literarias y culturales del Báltico oriental, en particular la lituana, sobre la que me detendré más, no me parece inoportuno proporcionar algunas coordenadas histórico-culturales que informen sobre las vicisitudes propias de esa zona de Europa. Considero útil, pues, comenzar con una digresión -debidamente comentada- de los elementos históricos y literarios más relevantes. De este modo se entenderá mejor de qué quiero hablar, sobre todo porque de la historia de los Países Bálticos, en efecto (y cito 
DINI

aquí Czesław Miłosz (1959), premio Nobel de literatura en 1980) "los libros y manuales dan pocas noticias, y casi siempre erróneas", y porque, como es notorio, baltica (scilicet lituanica et lettica) non leguntur. Es más: pese a mi esfuerzo para ser sintético, deberé mencionar muchos nombres de autores poco conocidos.

\title{
2. El Gran Ducado de Lituania como "moderna Alejandría"
}

A menudo, al referirse a la situación de la Lituania medieval, la del Gran Ducado de Lituania, se la compara con una moderna Alejandría. Me atendré a la descripción de uno de los intelectuales lituanos más conocidos, Tomas Venclova (1972a), que ha escrito:

\begin{abstract}
A los lituanos les gusta explicar, pero no siempre consiguen aclarárselo a los extranjeros, lo compleja que es la amalgama de culturas que existía en la denominada Lituania histórica y en la región de Vilna... No para todos los habitantes de este país resulta tan claro como pudiera parecer lo que fue aquella sutil mezcolanza, el conglomerado de lenguas, tradiciones y comportamientos, incluso el conglomerado genético del que surgirían grandes poetas y que apenas tiene parangón en la Europa occidental. Irlanda es una analogía imperfecta; tal vez convendría remontarse a Alejandría. Allí se producía un encuentro de culturas, se reflejaban unas en otras, pero al mismo tiempo se educaban recíprocamente. La de sustrato más antiguo, pero también la más joven, la que ha acabado de desvelarse en el siglo XX, fue la lituana.
\end{abstract}

Una situación análoga se da, bien es cierto, en todo el macrocontexto del Báltico oriental. Baste recordar que el caso de la Livonia plurilingüe era un topos recurrente en varias Descriptiones Livoniae de la época humanístico-renacentista (cf. Dini 2010: 447-524).

El Gran Ducado de Lituania fue, pues, un potencial melting-pot medieval colocado en el centro del continente. Bajo Gedeminas, acogió a muchos prófugos y refugiados de diversos lugares de Europa (hoy hablaríamos de inmigrantes; no recibió pateras por la limitación de su frente marítimo). Después de 1492 encontraron refugio allí muchos judíos, pero también personas perseguidas por no pocas herejías, gracias a la gran tolerancia profesada por el Gran Duque. ${ }^{2}$ Pero sigamos leyendo a Tomas Venclova (1972b):

2 La profesión de fe y tolerancia del Gran Duque Gedeminas figuran en una carta al legado papal: "Christianos facere deum suum colere secundum morem suum, ruthenos secundum ritum suum, polonos secundum morem suum et nos [Lituanos] colimus deum secundum ritum Nostrum, et omnes habemus unum deum”. Cfr. V. Pašuto, I. Štal, 1966; P. Rabikauskas, 1969. 
Lenguas, literaturas y nacionalidades en Lituania ( $y$ en el Báltico oriental)

El Gran Ducado de Lituania fue uno de los organismos más originales de la historia de Europa. Aunque fuera casi mil años más joven, se podría comparar con aquellos estados que se crearon en la época de la migración de los pueblos. Un conglomerado de regiones paganas y cristianas, quince veces mayor que el territorio étnico lituano, bastante inestable. Después del bautismo, el elemento polaco, al penetrar en Lituania, no se adaptó en absoluto a la situación cultural que encontró, pero se esforzó para adaptarla a la suya. El sistema religioso pagano, por ejemplo, fue aniquilado hasta el punto de que hoy es muy difícil reconstruirlo científicamente. Se polonizaron muy pronto las clases más altas de la sociedad. Se polonizó incluso el modelo de sociedad. Pero la integración de Lituania en la esfera de la cultura europea estimuló a los lituanos para afianzar su especificidad. Este afianzamiento se plasmó en el mito del origen [romano] de los lituanos, que se diferenciaba de la génesis de los demás pueblos.

Del cuadro así delineado emerge un dato importante que conviene subrayar: la situación de fuerte multiculturalidad y plurilingüismo que caracteriza al conjunto del área báltica desde su primera aparición en la escena histórica. Tal estado de cosas, combinado en el tiempo con numerosos fenómenos de sobreimposición lingüística (por el alemán, el polaco, el ruso y el sueco y, al final, nueva y prolongadamente por el ruso), determinó un "retraso" en la plasmación escrita de las lenguas autóctonas (lituano, letón, estonio) ${ }^{3}$.

\section{Ortsgebundenheit $y$ Sprachgebundenheit en la literatura lituana}

Para el tema que nos interesa examinar, ha llegado el momento de hacer en el seno de la baltosfera moderna y contemporánea una instructiva distinción entre literatura ortsgebunden y literatura sprachgebunden.

\subsection{Ortsgebundenheit o líneas creativas relacionadas con la Lituania histórica o mítica}

El resultado de la Ortsgebundenheit es una literatura centrada en una realidad territorial del Báltico oriental, real o imaginaria, pero que usa los recursos lingüísticos de otras tradiciones cultural-literarias que perseveran en aquel mismo territorio, hasta el punto de que ha quedado y queda encauzada y reconocida en otras literaturas.

3 Los primeros testimonios de las lenguas del Báltico oriental son de la segunda mitad del siglo XVI, en el contexto de la Reforma protestante en aquellas tierras. Sin embargo, el lituano, sobre todo, pero también el letón, aún conservan hoy unas características lingüísticas arcaicas: son las lenguas más arcaicas y conservadoras de la familia indoeuropea que todavía se hablan. 
DINI

Ejemplarizada en Lituania, esta situación marca muchas líneas de irradiación que con el tiempo se han desarrollado sobre una base alóglota, es decir, distinta del lituano. Las líneas principales, brevemente ilustradas, son estas:

a) Línea latino-lituana (Sarbievius, 1595-1640, el Horacio del norte de Europa; Hussovianus, 1475/85-después de 1533; y muchos otros autores de la época humanístico-renacentista).

b) Línea ruski-lituana (la abundante literatura escrita en la lengua denominada "eslavo cancilleresca" o, si se prefiere, en ruteno, durante los cuatro o cinco siglos de existencia del Gran Ducado de Lituania).

c) Línea polaco-lituana (en incremento a partir de 1569, después de la Unión de Lublín, e importantísima a partir del Romanticismo, en la que encontramos a Adam Mickiewicz, 1798-1855; Cyprian Norwid, 1821-1883, y otros, y conduce hasta Czesław Miłosz, 1911-2004).

d) Línea ruso-lituana (recordaré solo al poeta simbolista Jurgis Baltrušaitis senior, 1873-1944).

e) Línea germano-lituana (con Hermann Sudermann, 1857-1928, o con Johannes Bobrowski, 1917-1965, el poeta de Sarmatia, además de algunos prusianos y, en general, de la Lithuania Minor en Litauische Clavier, 1966).

f) Línea franco-lituana (bien representada por Oskar de Lubicz Miłosz, 1877-1939, y más tarde por Algirdas Julien Greimas, 1917-1992, hasta Jurgis Baltrušaitis junior, 1903-1988, y otros (entre ellos puede tener cabida Lokis ['El oso', 1869] de Prosper Mérimée, ambientado en Samogitia).

g) Línea hebreo-lituana (de la escuela cabalística de Gaon de Vilna, hasta Emmanuel Lévinas, 1906-1995; y también con presencia literaria actual tanto en Lituania [Markas Zingeris, n. 1947], como en Israel [Icchokas Meras, 1934-2014]).

Todas las líneas creativas citadas -e incluso otras posibles- han estado y están relacionadas estrechamente con Lituania como realidad histórica o mítica, y siempre como ámbito o fundamento identitario, independientemente de la que históricamente hayan elegido para expresarse.

\subsection{Sprachgebundenheit o digresión (mínima) sobre la literatura lituana}

El resultado de la Sprachgebundenheit es, en cambio -y evidentemente- una literatura que se ha expresado en una lengua autóctona del Báltico oriental. Aquí es, precisamente, donde debería comenzar el presente discurso: a partir de las vicisitudes propias de las literaturas expresadas en las tres lenguas principales del Báltico oriental (lituano, letón, estonio), que ejemplificaré seguidamente, sobre todo en el caso lituano. 
Lenguas, literaturas y nacionalidades en Lituania ( $y$ en el Báltico oriental)

\subsubsection{De Donelaitis al siglo XX}

Después de siglos de literatura oral y unos ciento cincuenta años de literatura escrita religiosa, tanto reformada como católica, la primera obra de tema profano que surgió en la literatura lituana fue la de Kristijonas Donelaitis (1714-1780). ¿Quién era? Teólogo protestante, figura poliédrica de literato y científico, activo en la Lithuania Minor (es decir, en el territorio lituanófono del ex Ducado de Prusia), entre 1765 y 1775 escribió su obra principal (2569 hexámetros) titulada Metai ('Las estaciones del año'), dividida en cuatro partes: "Los gozos de la primavera”, "Las labores del verano”, "Los bienes del otoño”, "Los afanes del invierno". Este poema, donde cuenta un año en la vida del campesinado lituano de Prusia, fue incluso escenificado en 2006, con gran éxito, por el director teatral Eimuntas Nekrošius.

El poema de Donelaitis compartía y elaboraba originalmente un difundido modelo de la "poesía de las estaciones" (poesía descriptiva del siglo XVIII); Metai es parte integrante del circuito literario europeo de su tiempo ${ }^{4}$, pese a campar en solitario en el panorama de las letras lituanas. Como consecuencia de los acontecimientos históricos, le siguió un largo período de decadencia que se prolongó durante casi todo el siglo XIX. Son los años en que tienen lugar las particiones de Polonia-Lituania hasta que queda integrada en la Rusia zarista; los años en que, según los planes centralistas de los zares, Lituania hubiera debido quedar limitada a una expresión geográfica. Son los años del spaudos draudimas, es decir, la prohibición de imprimir en lituano con catacteres latinos y la imposición del alfabeto cirílico; son los años de los knygnešiai-literalmente, 'portalibros' (de knygà 'libro', y néšti 'llevar')-, fenómeno único en el contexto europeo gracias al cual, durante años, los libros lituanos en alfabeto latino, impresos fuera de Rusia, eran introducidos de contrabando en el país por unos dos mil "portadores de libros"; muchos de ellos, por su apego a la lengua y a las letras patrias, fueron deportados a Siberia. Pero también eran los años en que el movimiento patriótico iba organizándose en la clandestinidad -en las tres realidades del Báltico oriental-y cuando, tras repetidas rebeliones, se llegará a

4 Limitándonos esencialmente al siglo XVIII, en España empleó este modelo Baltasar Gracián (1601-1658) en la primera parte ("En la primavera de la niñez y en el estío de la juventud") de El Criticón (1651); en Escocia lo hizo James Thomson (1700-1748) con The Seasons (1726-1727), obra traducida al alemán (1745) que sería la base del oratorio de Haydn; en Francia hay que recordar al menos a Jean-François de Saint-Lambert (1716-1803) con Les saisons (1781), así como a Claude Peyrot, que escribió Los cuatre sosous (1781) en occitano; en Italia lo cultivaron autores menores como Francesco Ghilardelli Delfò (1745-1815), activo en Padua, que publicó Le quattro stagioni (1804). La primera versión íntegra en castellano del poema de Donelaitis se publicó en edición y traducción de Carmen Caro Dugo (Donelaitis 2013). 
DINI

las declaraciones de independencia, ya en el siglo XX: el 16 de febrero de 1918 en Lituania, el 24 de febrero de 1918 en Estonia, y el 18 de noviembre del mismo año en Letonia. Ello ocurrió a causa de las cambiantes condiciones históricas, después de que todo el Báltico fuera ocupado y devastado repetidamente por ejércitos enemigos de signo opuesto, como bien explica Marguerite Yourcenar en Le Coup de grâce (1939).

Conviene subrayar la estrecha relación que se produce entre la conciencia nacional y la conciencia lingüística. Las reivindicaciones lingüísticas del movimiento patriótico lituano, y de todos los bálticos orientales, han acompañado siempre a las reivindicaciones nacionales (entre otros muchos, cfr. Niendorf 2012).

Surge aquí espontáneamente la pregunta de si tal estado de cosas afecta realmente solo a los bálticos y los demás pueblos de la Europa del Centro o si puede aplicarse también en otros lugares. De hecho, la larga gestación de un Estado lituano soberano moderno tiene lugar -sin duda con retraso, pero con mecanismos análogos-durante la formación de varias naciones europeas. No difiere de lo que ocurrió en otras realidades, empezando por la de Italia, donde la centralidad del debate sobre la lengua (conocido como "cuestión de la lengua") supuso una especie de sustitutivo de la aún no conseguida unidad del país. Efectivamente, no es menos cierto que otros factores o coyunturas históricas, la especificad lingüística, su "diferencia”, puede producir identidad y tradición, sobre todo en contextos de opresión política. Y la literatura, al estar obviamente más vinculada que otras artes a la lengua que la expresa, se ha resentido y se resiente en mayor medida de la situación (pese a toda la retórica a la que puede dar lugar).

No hay duda de que en esas vicisitudes lituanas se puede detectar el despliegue de un valor romántico con espoleta retardada -epigónico, si se prefiere-. En todo caso, es lo que ocurrió en el contexto báltico oriental, y eso es lo que realmente cuenta.

Si pudiera parecer exagerada o fuera de lugar - pero, sinceramente, no veo por qué- la aproximación entre el Atgiminas lituano, el Atmoda letón o el Ärkamisaeg estonio con respecto al Risorgimento italiano, encontraríamos paralelismos que encajarían muy bien. No faltan semejanzas entre realidades culturales "menores" en las periferias del Viejo Continente, como el Báltico oriental y el este de la Península ibérica: de hecho, se pueden establecer paralelismos, por ejemplo, con la Renaixença catalana.

Incluso el referido "retraso" (no encuentro un término más adecuado, pero debería entenderse en sentido neutro, sin el juicio de valor que suele acompañarlo) objetivo de las literaturas autóctonas del Báltico oriental se pone en evidencia, pues, al compararlo con otras “áreas laterales” de Europa. En efecto, siguiendo en la línea de las comparaciones, se encuentran numerosos paralelismos con la 
situación catalana. Ambas comunidades lingüísticas - la lituana y la catalanaconocieron, más o menos en la misma época, el abandono de la lengua por parte de las clases altas, pues en ambos casos fueron sometidas a reiterados intentos de sustitución lingüística y ambas han desarrollado un gran interés y mucha sensibilidad por las ideas eco-idiomáticas. No es difícil encontrar figuras literarias y intelectuales muy similares tanto en los tonos como en los temas y las formas que emplearon. Para citar dos ejemplos, pienso en los poetas Jonas Mačiulis (1862-1932), un sacerdote más conocido como Maironis, por un lado, y mossèn Jacint Verdaguer (1845-1902, también sacerdote), por el otro; o en Simonas Daukantas (1793-1864) y Motiejus Valančius (1801-1875), por una parte y, por ejemplo, Josep Yxart (1852-1895), Joaquim Casas i Carbó (1858-1943) y Carles Riba (1893-1959), por la otra. Son análogas también las obras de esdandarización de Jonas Jablonskis (1860-1930) y Pompeu Fabra (1868-1948). Y las comparaciones no acabarían aquí... ${ }^{5}$

Por las razones aducidas y por otras que se plantearán más adelante -no solo, pues, por deformación u obsesión personal como lingüísta- me resulta difícil hablar de la identificabilidad de una literatura nacional prescindiendo de la lengua. Ello sería posible, si acaso, si se tratara de las literaturas (y culturas) que se expresan en "lenguas imperiales" -según la feliz expresión de Claude Hagège (2000: 143-147)-, pero no en el caso de muchas de las realidades literarias (y culturales) de la Europa centro-oriental -tanto la checa, como recordaba Kundera en el texto que abre este artículo, como las del Báltico oriental, y otras. En la identificabilidad de estas realidades literarias (y culturales) la lengua no es un epifenómeno, sino un concepto central.

\subsubsection{La primera mitad del siglo $X X$}

Volvamos a la situación en Lituania. Con la independencia, se asiste a una reorientación general de la cultura, sobre todo de la literatura, hacia modelos importados de la Europa occidental. Recordaré la corriente poética de los denominados Keturvejininkai ('Los de los cuatro vientos'), una versión local del futurismo que tuvo como principal exponente al poeta Kazys Binkis (1893-1942), y la de los poetas Žemininkai (los 'Terrestres'), vinculada a temáticas existencialistas y del exilio (V. Mačernis, J. Kèkštas, A. Nyka-Niliūnas, H. Nagys).

5 Junto a sustanciales semejanzas superficiales entre Lituania y Cataluña se dan, obviamente, sustanciales y profundas diferencias: en ningún momento de su historia Lituania ha conocido una importante burguesía mercantil como Cataluña (en parte, ni siquiera como Livonia, aunque esta estuviera en manos del componente alemán de la población), sino que ha permanecido siempre anclada, desde los puntos de vista social y cultural, en el campesinado. 
DINI

Pero se trata de la formación (o del intento inconcluso de formación) de un modelo literario autónomo que tuvo sus mejores exponentes en Vincas Mykolaitis-Putinas (1893-1967), Vincas Krèvè-Mickevičius (1882-1954) y Jonas Biliūnas (1879-1907), entre otros. Un modelo literario autónomo fundamentado sobre la lengua (elemento no "secundario", sino decisivo) y la ambientación, realia, referencias históricas y una mitología pagana precristiana, con un fuerte componente de oralidad, sobre todo en la poesía (herencia de muchos siglos de tradición oral).

En la Lituania de entreguerras se consigue -con el retraso habitual, mencionado anteriormente- un modelo literario autónomo inspirado en la cosmovisión específica de un Volk, que bien puede denominarse "modelo literario nacional" e identificarse como tal, con unas características que en otras realidades lingüístico-culturales ya se había establecido con el Romanticismo.

Pues bien, este modelo duró lo que un soplo. En el Báltico oriental la historia se repite una vez más (¡y no como una farsa!) y las tres Repúblicas se ven nuevamente implicadas en los planes de reparto territorial de las grandes potencias, esta vez según los protocolos secretos del pacto Molotov-Ribbentrop. Los hechos históricos son bien conocidos, por lo que no me detengo en ellos ${ }^{6}$. Las consecuencias para la clase intelectual y para cualquier forma de resistencia al cambio fueron sencillamente aniquilantes. Para entenderlo mejor es imprescindible la novela de Czesław Miłosz, Rodzinna Europa (1959).

\subsubsection{La segunda mitad del siglo $X X$}

Empieza una nueva fase de la literatura lituana. En 1953 es una vez más Czesław Miłosz quien escribe:

El problema de los pueblos bálticos es diez veces más importante para el poeta contemporáneo que cualquier cuestión de estilo, métrica y metáfora.

En cualquier caso, en la nueva situación el "modelo literario autónomo o nacional” fue, obviamente, vilipendiado, y el que lo sucedió se dispersó por tres cauces que raramente confluyeron: la literatura oficial, más o menos afín al régimen; la disidente dentro del país, clandestina, y la del exilio, de la diáspora, dispersa. Cada uno de estos cauces merece un breve comentario.

Una vez más, sometido forzosamente a la imposición estatal rusa, ahora soviética, el mundo literario báltico sufre unas transformaciones profundas e

6 Entre una vasta bibliografía sobre el tema señalo, además de la edición especial de Lituanus (35-1/2, 1989), la obra de J. Urbšys, Lietuva lemtingaisiais 1939-1940 metais, Vilna, Mintis, 1989, traducida a muchas lenguas. 
Lenguas, literaturas y nacionalidades en Lituania ( $y$ en el Báltico oriental)

inéditas, comunes a todas las demás repúblicas socialistas de la URSS y, aunque de modo menos acentuado, a las otras naciones del denominado "bloque del Este”. Por una parte ha de aceptar la imposición "desde arriba” del modelo del realismo socialista, la adaptación a determinadas temáticas ejemplares y la aplicación de la fórmula susloviana que requería el conocido principio "nacional en la forma, soviético en los contenidos". Por otra parte se comparte y se desarrolla un modelo difundido en todas las literaturas disidentes de detrás del "telón de acero", en una situación de "resistencia pasiva" que va desde el samizdat al uso de la escritura entre líneas (la llamada "lengua de Esopo").

Por muy paradójico que nos pueda parecer, los lituanos y los otros bálticos orientales encarnaron durante aquellos decenios la idea de poesía como “proyecto existencial de la nación”. Podrá decirse que esta es una lectura aberrante (un falseamiento de la conocida afirmación de Paul Celan). Se puede reaccionar como se prefiera, pero eso no quita que las cosas fueran así. No se explican de otro modo las enormes tiradas (agotadas) de libros de poesía de vates nacionales de la época, como Justinas Marcinkevičius (1930-2011) o Bernardas Brazdžionis (1907-2002), para limitarme a dos nombres, ni la participación masiva, rayana al misticismo (soy testimonio presencial de ello), en las lecturas de poesía durante los largos años de la resistencia pasiva.

La conciencia nacional y la conciencia lingüística, literaria en primer lugar, van una vez más al unísono. También para los escritores lituanos y bálticos en general, refugiarse en la lengua significó, a la vez, asilo y exilio.

Asilo para los escritores disidentes que, por diversas razones, dentro del país, utilizaron la escritura entre líneas. Conviene recordar que en el mundo totalitario, hostil a cualquier forma de literatura, el poeta es el último que sobrevive, pues se silencia, por este orden, al periodista, al sociólogo, al historiador, al novelista y al crítico (cfr. Orwell 2000).

Exilio, en cambio, para quienes "se establecen en Occidente", según la fórmula eufemística estándar utilizada en las enciclopedias soviéticas. En la literatura del exilio, precisamente, intentó sobrevivir el efímero "modelo literario nacional", sin conseguirlo, salvo en el caso de algunos autores de la primera generación de expatriados.

En estos casos, para anclarse mejor en la lengua, la literatura lituana del exilio se alimentó siempre -y como último recurso- del ideal de una Heimat perdida. Pero en las generaciones siguientes ya se observa un proceso de erosión de la hermosa ilusión de poder acunarse en la familiaridad de la lengua propia, por lo que los escritores del exilio fueron los primeros que experimentaron en la Heimatlosigkeit de su día a día en el extranjero (mayoritariamente en los Estados Unidos) las limitaciones de la lengua materna. En este contexto aparecen también, en la obra de algunos escritores de tercera generación, los primeros 
DINI

síntomas de extraterritorialidad (en el sentido de Georges Steiner). Además del caso más notable, el del poeta y ensayista Tomas Venclova (cfr. Mitaitė 2002), me parece otro claro ejemplo de opción cosmopolita y de adhesión a modelos literarios ajenos a la tradición el narrador Saulius Tomas Kondrotas (n. 1953). ${ }^{7}$

\subsubsection{La protesta identitaria}

En una entrevista del invierno de 1989 -sin presagiar en absoluto lo que ocurriría poco después-, Czesław Miłosz se preguntaba y se respondía a sí mismo esto (cfr. Kudaba 1989):

Me pregunto: si estos estados alcanzan la normalidad, si sus poetas y escritores se pueden librar de la violencia de la escritura política, si escriben sobre los ideales de la vida, de amor y de muerte, ¿̇erá su literatura como la de la Europa occidental o la de América?... Respondo: no. Y no lo debe ser, ya que nuestra experiencia es el pasado histórico. Una experiencia terrible que debe suponer una enseñanza.

Al cabo de un año de estas pesarosas palabras -después de los trágicos hechos de 1990-, empezó el último acto, cronológicamente hablando, de los acontecimientos literarios bálticos.

La crítica contemporánea, sobre todo en los ámbitos académicos estadounidenses, intenta desarrollar una interpretación de las experiencias lituana, letona y estonia de la segunda mitad del siglo XX (en realidad, del período soviético) en términos de "literatura postcolonial" (cfr. Kelertas 2006). Recuperando así la retórica de las "últimas colonias de Europa" - el afortunado eslogan de la protesta identitaria que estalló a finales de los años 80-, tenemos en nuestros días la perspectiva crucial.

Pese a presentar posiciones contrastadas, esta es la perspectiva a través de la cual los propios bálticos orientales intentan comprender su pasado más o menos próximo y atraer la atención de un auditorio más amplio en la fase inmediatamente sucesiva a la restauración postsoviética de sus estados soberanos.

\subsubsection{La situación actual}

Recapitulando a vuelapluma, se puede decir que, tras una fase de gestación (muy larga) y de realización (muy breve) de un modelo de literatura (y cultura) que podría definirse como "nacional", el panorama actual de la literatura lituana ha cambiado de forma determinante. Investigar hoy en día sobre la literatura

\footnotetext{
Se ha publicado en castellano su novela El ojo de la serpiente, trad. de P. Giralt Gorina,
} Barcelona, Seix Barral, 1992 (titulo original, Žalčio žvilgsnis, Vilna, Vaga, 1981). 
producida en el país significa aproximarse a un lugar efervescente, discursivo, múltiple y variado, recorrido por corrientes asistemáticas y enfrentadas, inestables e incluso inéditas en aquellas latitudes.

La última provincia de Europa, en sentido cronológico, anclada aún en parte a la Europa de ayer es, pues, también la ultima -tal vez sería preferible decir nouissima- provincia que se ha incorporado a la Europa literaria de nuestros días.

Se cultivan formas, temas, géneros y modelos que se pueden hallar también en otros lugares, en otras literaturas. Dicho más concisamente: despunta una floreciente literatura femenina, presente también antes, pero que ahora ha eclosionado (cfr. Daujotytė-Pakerienè 2001; Kolevinskienè 2011). La poesía resiste sólidamente. La novela tradicional, menos, mientras que se impone una escritura híbrida entre narración y reflexión ensayística. En cualquier caso -dato no tan obvio en esta historia-, se continúa escribiendo en lituano.

Por una parte, la recuperación de la solvencia política y estatal ha hecho que los escritores de aquellas tierras abrieran los ojos a un mundo decididamente otro, y ha pillado desprevenidos a muchos de ellos, especialmente los pertenecientes a las generaciones de mayor edad. Por otra parte, se asiste a fenómenos nuevos que plantean cuestiones inéditas: ise pueden considerar acaso pertenecientes a la literatura lituana al prosista canadiense Antanas Šileika o a los poetas Ray Philippe e Irena Guilford, que escriben en inglés, solo porque son de origen lituano?, o ¿cómo debería considerarse al actual best-seller Habian apagado incluso la luna, de la lituana de Michigan Rūta Šepetytė? Al contrario, Jonas Mekas (n. 1922), el padre del cine underground, reside desde hace muchísimos años en los Estados Unidos, pero siempre ha escrito sus versos en lituano. Y, al mismo tiempo, ¿ icómo deben ser considerados todos -y no son pocos- los escritores y poetas que escriben en lituano pero residen en Francia, Bélgica, el Reino Unido o Israel?

En el nuevo contexto, el "modelo literario nacional" es incapaz de recomponerse, al menos en las formas tradicionales conocidas anteriormente. De hecho, en 1990 el escritor Ričardas Gavelis (1950-2002), autor de Vilniaus pokeris ['El póquer de Vilna'], novela traducida a varias lenguas, respondiendo al cuestionario de una revista lituano-estadounidense, declaraba: "Tengo la esperanza de que los intelectuales libres sepan conducir el proceso de sincronización de la cultura lituana con la del resto del mundo" (cfr. Donskis 2005: 7). ¿Quizá solo se trate de conseguir esto - es decir, que baste la aproximación, rápida pero isócrona, a formas, temas y modelos que se encuentran en otros lugares- para poder afirmar que la literatura lituana ya no es tan nacional como antes...? Según Tomas Venclova, sí. Ha declarado abiertamente que hoy la literatura lituana no puede estar conectada solamente a Lituania. Y el intelectual, sociólogo y politólogo Leonidas Donskis piensa lo mismo al considerar que el lituano es un pueblo de 
DINI

la diáspora, exteriorizado y des-territorializado. Una vez más, la única referencia "nacional" se limitaría a la lengua... ${ }^{8}$

\section{Pensamientos en orden abierto}

Llegado al final de esta sumaria digresión sobre la literatura lituana, me parece oportuno hacer algunas consideraciones generales que puedan aportar algo más al debate general sobre literatura y nacionalidad, a la luz de una experiencia local y específica como la que he tratado de explicar e ilustrar. Propondré, pues, algunas ideas para la reflexión.

La primera es que cuando nos preguntamos si todavía existe una literatura nacional, probablemente el término sobre el que deberíamos poner énfasis no es literatura, sino nacional.

Cuando nos preguntamos si esa literatura nacional se ha convertido en una categoría obsoleta, ¿no será que lo hacemos porque percibimos que lo que ha quedado obsoleto es la categoría de nación? (Sería preocupante lo contrario, pero no faltan quienes se plantean el problema y se preguntan qué sentido tiene la literatura en la sociedad postindustrial y el mundo digital.) La pregunta que debemos hacernos quizá no sea si existe (aún) una literatura nacional, sino si existe (aún) la nación.

Pero, ¡cuidado!: esta pregunta, así como su motivación, no serán comprendidas en todas partes del mismo modo. Es muy probable que se advierta mayoritariamente la insuficiencia de expresarse en términos de literatura nacional allí donde la categoría de nación se haya debilitado. Viceversa, allí donde (todavía) tenga sentido hablar de nación, es probable que (todavía) tenga sentido hablar de literatura nacional.

La cuestión se complica si se considera lo que dice la ciencia política contemporánea. En efecto, siguiendo la autorizada opinión de Immanuel Wallerstein (cfr. Balibar, Wallerstein 1991), en el sistema-mundo moderno encontramos una inversión del planteamiento (tardío) romántico, por lo que conceptos como pueblo y nación se habrían formado después (y no antes) de la constitución de un Estado: "El Estado ha precedido a la nación, y no al revés, contrariamente a un mito ampliamente difundido". Naturalmente, en su esquema general, el politólogo estadounidense no puede tener en cuenta los casos de "estatalidad intermitente", interrumpida y reconstruida repetidas veces en el curso de la

8 Es la opinión expresada también en su documentada digresión sobre la reciente literatura de la emigración lituana por Satkauskytè 2011. En Lituania, por el contrario, el tema es objeto de reflexión crítica, por ejemplo en Tamaševičius 2011ab. 
historia y típicos, precisamente, de las repúblicas del Báltico oriental. Como consecuencia de ello, por específicos y trágicos acontecimientos históricos, las bálticas han sido varias veces relativamente jóvenes (o, a menudo, "rejuvenecidas") y, por ende, también, y aún, potencialmente sensibles a la categoría de nación hasta una época relativamente reciente.

Retomando el hilo general del discurso, todavía no es inverosímil pensar que se continúe considerando literatura nacional algo que va perdiendo, o que ya ha perdido, los elementos característicos de una literatura nacional entendida al modo tradicional. Es bien sabido que las palabras, como etiquetas, sobreviven a los conceptos que vehiculan, de modo que se siguen llamando de la misma manera, se continúan utilizando las mismas palabras para designar contenidos superados u obsoletos y, de hecho, modificados. En cada lengua encontramos muchos ejemplos de pérdida de motivación o, simplemente, de cambio de motivación. Es verosímil, pues, que la denominación literatura nacional designe contenidos ya inestables, en vía de modificación total o parcial, y que ésta experimente en las diversas comunidades lingüísticas fenómenos (que considero banales) de desgaste semántico. El hábito mental difícilmente muere, y las lenguas (aún) no se han adecuado a la nueva situación.

Todo esto es, pues, bastante probable. Si acaso, convendrá tener presente que un proceso de este tipo - una vez establecido que se esté realizando- no se da ni en los mismos tiempos ni de la misma manera, ya que la dinámica interna de cada comunidad lingüística es muy diferente. Es probable que cada una de las "comunidades literarias" -si se me permite el analogon-se mueva, por así decirlo, con motores distintos y evolucione con tiempos también distintos.

No debe, pues, menospreciarse la dificultad que se perfila en el horizonte cada vez que se pretenda, simplemente, extender categorías, válidas si acaso para amplias macroáreas del mundo occidental, incluso en distritos de una Europa donde la historia ha determinado situaciones socioculturales que no pueden reducirse a las más difundidas en otros ámbitos geográficos. Si así se hiciera, no solo se obraría impropiamente, sino que se nos condenaría a la incomprensión. Y ya se sabe que la incomprensión del presente nace fatalmente de la ignorancia del pasado.

La trayectoria de la identidad lituana nos ayuda a comprender la historia del siglo XX en toda la Europa central: aquel hervidero de lenguas y literaturas, aquella enorme variedad de culturas y pensamientos reunidos en una reducida área territorial. Actualmente, para los intelectuales de dicha área, el desafío es crear una identidad báltica regional que sea a la vez global y abierta, pero en la que se pueda cartografiar el pasado y el presente sobre la base de criterios completamente nuevos. 
DINI

Leonidas Donskis (n. 1962), politólogo y sociólogo de la Universidad Vytautas Magnus de Kaunas, es un defensor convencido y perseguidor empedernido de una identidad para la región báltica en su conjunto territorial y cultural. Donskis (2009) ve acertadamente en el patriotismo (y el nacionalismo) literal entendido como alternativa al nacionalismo anti-conservador y radical, al desprecio imperialista respecto a las pequeñas naciones- una creación histórica de la región báltica que se ha desenvuelto en la historia con la contribución de grandes pensadores liberales de la misma región, como Kant, Herder, Schiemann o Berlin, y de teóricos lituanos del liberalismo, como Vytautas Kavolis (1930-1996).

En otras palabras: el Báltico oriental se ofrece una y otra vez como laboratorio en el que se pueden experimentar los desafíos y las tensiones de la modernidad. Esta ha sido también la concepción que mantuvo siempre el historiador británico John Hiden (1940-2012), de la que dan fe sus escritos (cfr. Hiden, Loit 1987; Hiden, Salmon 1991). Convencido de que la Europa de nuestros días ha de afrontar desafíos muy similares a los que se les presentaron a los Estados bálticos en el breve período de independencia entre las dos guerras mundiales, sobre todo la emigración y la formación de nuevas y grandes comunidades étnicas y culturales, Hiden afirmaba que los Estados bálticos tienen una experiencia política de la que carece, o no comprende, Occidente. En las actuales condiciones de inseguridad y necesidad de reforzarse y cuidar de sí misma, Europa podría sacar provecho de la experiencia báltica.

Más aún: la experiencia báltica y lituana -como la de otras muchas "pequeñas patrias"- enseña algo en lo que conviene insistir y que debe valorarse atentamente: la importancia del factor lengua, o sea el estrechísimo vínculo entre conciencia nacional y conciencia lingüística, una circunstancia que entre nosotros no se ha dado nunca por descontada; mejor dicho: la conciencia nacional y la conciencia (socio)lingüística siempre han ido al unísono. Sin embargo, esta relación no es, por supuesto, un privilegio solo de las pequeñas patrias. Cada literatura, en sus orígenes, constituyó un vínculo mítico con la lengua nacional; la nación misma es un elemento fundacional que se transforma, es una promesa de identidad en construcción...

Y si no puede negarse que también esta periferia europea -el ámbito cultural báltico oriental- se halla actualmente dentro de ese gran fenómeno de convergencia (globalización, si se prefiere) entrópico de las expresiones literarias del Planeta, la lengua en que se expresa una determinada literatura sigue sin ser un mero apéndice epifenoménico; por el contrario, en el cuadro que acabamos de delinear, las variedades lingüísticas permanecen como un factor sintrópico e identitario de pertenencia muy vital. 
Las objeciones son bien conocidas desde hace tiempo. Numerosas veces, a lo largo de la historia, las culturas minoritarias han sido "exhortadas" a utilizar códigos de expresión lingüística mayoritarios, diferentes según los lugares, pero siempre como consecuencia de una misma operación cultural-hegemónica. Recuerdo una anécdota sobre Miguel de Unamuno, que preguntaba medio en serio, medio en broma, a su amigo Joan Maragall, por qué en lugar de utilizar el máuser del castellano prefería usar la triste espingarda del catalán. Le respondió Eugeni d'Ors con no poca agudeza:

Unamuno tiene razón: como arma de su imperialismo el castellano es un máuser. Pero para otras guerras hacen falta otros máuser más máuser que el castellano, n'est-ce pas, my dear?

Sin saberlo, Eugeni d'Ors había prefigurado así el europanto, tan difundido hoy entre los funcionarios de Bruselas ( $y$ teorizado por Diego Marani; cfr. Gobbo 1998).

\section{Conclusión}

Concluyo. Probablemente no sea la persona más autorizada para dar indicaciones a los estudiosos de la literatura; sin embargo, quisiera decir una última cosa e partibus parvarum litteraturarum. En nuestras reflexiones no debería infravalorarse el horizonte "identitario" (y menos aún valorando más el "nacional"). La cuestión más general es, precisamente, la relación entre la identidad, la lengua, la literatura y la cultura de pertenencia. Para limitarnos al Viejo Continente, se podría invertir la pregunta inicial y plantearse si es posible identificar rasgos característicos para un estudio comparado de las literaturas diferente del de las "literaturas nacionales", pero que responda a las viejas, aunque siempre nuevas exigencias tanto de tipo lingüístico-identitario como de pertenencia.

Un especialista de este ámbito disciplinario inédito -¿cómo denominarlo?-, ¿de qué y de cuántas competencias debería estar dotado? ¿Qué literaturas y qué lenguas debería contemplar? ¿Disponemos de criterios para poder imaginar algo así, algo que se diferencie, por su novedad, de los métodos al uso de la Geistesy/o de la Sozialgeschichte, pero que continúe manteniendo válido y operativo el horizonte lingüístico-identitario?

Es bien sabido que, estando acostumbrados y siendo propensos a examinar las artes figurativas, y más aún la música, en un contexto supranacional, tropezamos con más dificultades - jay, la irreductibilidad del código lingüístico!cuando se trata de obras literarias. Y pese a ello, podemos examinarlas desde el 
DINI

punto de vista del microcontexto (con la cultura nacional de fondo) y del macrocontexto (con la cultura supranacional de fondo). Se trata de una invitación que viene de lejos, como es sabido; al menos de las reflexiones goethianas sobre la Weltliteratur, y son conocidos los intentos en este sentido. Desde la Philologie der Weltliteratur alemana (Curtius, Auerbach, Spitzer), que reaccionaba de modo universalizante al hipernacionalismo de su época, hasta los intentos más recientes, como la République mondiale des lettres de Pascale Casanova (1999), centrado en el modelo espacio/tiempo, o el atlas de la novela europea y los análisis de la forma novela de Franco Moretti (2001-2003). ${ }^{9}$ Cosas egregias todas ellas. Pero ¿dónde está, en estas perspectivas, el lugar de las literaturas minoritarias? (por no decir, más claramente: ¿dónde van a parar las literaturas minoritarias?). ¿Y cuál sería su peso en la constitución de un ideal súpercanon?

Desde una perspectiva minoritaria, una solución quizá pudiera ser la definición de un concepto de literatura europea (cfr. Domenichelli 2004). Un desafío utópico, ideológico, realista: sin duda, un proyecto útil para la construcción de una identidad europea que no podría prescindir, sino que podría surgir, precisamente, de la variedad de literaturas nacionales... Sin la menor duda, convendría trabajar sobre las coyunturas y los nexos, sobre la migración y la elección de modelos, géneros y filones de escritura; pero también sobre la historia de las traducciones y de las autotraducciones (Nabokov, Kundera, etc.), sobre la "fortuna" de las obras y los autores en los distintos países, sobre las influencias recíprocas; incluso podrían encontrar su espacio algunos aspectos de las historias editoriales. De este modo quizá se pudiera establecer una cartografía de los mínimos denominadores comunes a una tradición literaria supranacional. Personalmente, no veo por qué no podría tenerse en cuenta también, para la construcción de una súper-retícula de este tipo, la subdivisión más tradicional en comunidades lingüísticas, puesto que se trata de un quid superable, es cierto, pero también irreducible.

Pues bien: he empezado este breve viaje por las literaturas del Báltico oriental, y en particular por la lituana, con una cita de Milan Kundera, y termino con otra del mismo autor que me parece bastante útil, ya que se puede conciliar con los distintos puntos de vista (cfr. Kundera 2002: 26-27):

9 Como es sabido, Moretti (2000), retoma operativamente las metáforas del árbol y de la ola y reconoce abiertamente su deuda con respecto a la glotología del siglo XIX que se desarrolló en los términos de la Stammbaumtheorie de August Schleicher (1821-1868) y de la Wellentheorie de Johannes Schmidt (1843-1901). 
Lenguas, literaturas y nacionalidades en Lituania ( $y$ en el Báltico oriental)

Toda obra toma una parte de su originalidad de la situación histórica en la cual está ambientada, pero su valor es visible, comprensible, individualizable, mensurable solamente en un contexto que supere a la propia nación.

Ello equivale a presagiar un equilibrio entre la historia ya construida y la historia que hoy está en construcción.

\section{Pietro U. Dini}

pietro.dini@unipi.it

Filologia Baltica

Dipt. di Linguistica

Via S. Maria 36

56126 Pisa

ITALIA

\section{Bibliografia}

AA. VV. 2011. No Men, no Cry. Contemporary Lithuanian Women's Prose. Vilna: International Cultural Programme Centre.

Balibar, E., Wallerstein, I., ed. 1991: Razza, nazione, classe: le identità ambigue. Roma: Edizioni associate.

Bojtár, E. 2006. Where is Central Europe. A Comparative Study of the Region's Literatures. - Lituanus, 52-1, 17-28.

Casanova, P. 1999. La République mondiale des lettres. París: Seuil.

Daujotytė-Pakerienè, V. 2001. Parašyta moterų ['Escrito por mujeres']. Vilna: Alma Littera.

Dini, P. U. 2010. Aliletoescvr. Linguistica baltica delle origini: Teorie e contesti linguistici nel Cinquecento. Livorno: Books \& Company.

Domenichelli, M. 2004. Europa, identità nazionali, identità europea e letterature comparate. - Letterature d'Europa e d'America, 1, 318-324.

Donelaitis, K. 2013. Las estaciones del año. Edición y traducción de Carmen Caro Dugo. Sevilla: Renacimiento.

Donskis, L. 2005. Loyalty, Dissent, and Betrayal: Modern Lithuania and East-Central European Moral Imagination. Ámsterdam, Nueva York: Rodopi.

Donskis, L. 2009. 99 Baltijos istorijos ['99 historias del Báltico']. Klaipèda: Druka.

Gobbo, F. 1998. Dirlo in Europanto. - Italiano \& oltre, 13, 226-231.

Hagège, C. 2000. Halte à la mort des langues. París: Odile Jacob.

Hiden, J., Loit, A. 1987. The Baltic States in International Relations between the two world wars. Nueva York: Longman publishing group.

Hiden, J., Salmon, P. 1991. The Baltic Nations and Europe: Estonia, Latvia and Lithuania in the twentieth century. Nueva York: Longman publishing group $\left[{ }^{2} 1994\right.$, Pearson education].

Hoskoveć, T. 2005. Lithuania as Paradigm: A Central European Destiny. - Lituanus, 51-1, 54-69. 
DINI

Yourcenar, M. 1939. Le Coup de grâce. París: Gallimard.

Kelertas, V., ed. 2006. Baltic postcolonialism. Ámsterdam, Nueva York: Rodopi.

Kolevinskienè, Ž. 2011. What is this thing called women's literature? - AA.VV., No Men, no Cry. Contemporary Lithuanian Women's Prose. Vilna: International Cultural Programme Centre.

Kudaba, Č. 1989. Česlovas Milošas - esu lietuviškai kaliforniškas poetas ['Czesław Miłosz: soy un poeta lituanamente californiano']. - Santara, '89 žiema, 77-80.

Kundera, M. 2008. Iannis Xenakis o il rifiuto integrale dell'eredità. - Un incontro, trad. de M. Rizzante. Milán: Adelphi, 88-89.

Kundera, M. 2002. Weltliteratur. - M. Rizzante, ed., Milan Kundera. Milán: Marcos y Marcos ('Riga', 20), 26-27.

Miłosz, Cz. 1953. Zniewolony umyst. París: Instytut Literacki - Kultura [Cfr. El pensamiento cautivo, trad. de E. Revol, Barcelona, Tusquets Editores, 1981].

Miłosz, Cz. 1959. Rodzinna Europa. París: Instytut Literacki.

Mitaite, D. 2002. Tomas Venclova. Speaking through signs. Vilna: Lietuvių literatūros ir tautosakos institutas.

Moretti, F. 2000. Conjectures on World Literature. - New Left Review, 1, JanuaryFebruary, 54-68.

Moretti, F. 2001-2003. Il Romanzo, 5 vols. Turín: Einaudi.

Niendorf, M. 2012. Zwischen historischer und ethnischer Nation: Die litauische Nationalbewegung und die Rolle der Sprache. - K. Maier, Hrsg., Nation und Sprache in Nord-Osteuropa im 19. Jahrhundert ('Veröffentlichungen des Nordost-Instituts', 9). Wiesbaden: Harrassowitz, 294-312.

Orwell, G. 2000. The Prevention of Literature. - G. Orwell, Essays. London: Penguin Books, 328-340.

Pašuto, V., Štal, I. 1996. Gedimino laiškai ['Las cartas de Gedeminas']. Vilna: Mintis.

Rabikauskas, P. 1969. Commentary to the 'Letters of Gediminas'. - Lituanus, 15, 4754.

Satkauskytè, D. 2011. Egzilinè (ne)tapatybè naujausioje lietuvių emigrantų literatūroje ['(No) identidad en el exilio en la literatura lituana de la emigración más reciente’]. Oikos. Lietuviu migracijos ir diasporos studijos, 12.

Tamaševičius, G. 2011a. Metaforos, kuriomis gyvi esame. Arba kaip kalbama apie grèsmes kalbai ['Metáforas por las que estamos vivos, o cómo se habla de las amenazas para la lengua']. - Naujasis Židinys-Aidai, 5, 308-313.

Tamaševičius, G. 2011b. Tauta gimusi iš filologijos, ir lingvistinio nacionalizmo fenomenas ['Un pueblo nacido de la filología y el fenómeno del nacionalismo lingüístico']. - Darbai ir dienos, 56, 143-152.

Urbšys, J. 1989. Lietuva lemtingaisiais 1939-1940 metais. Vilna: Mintis.

Venclova, T. 1972a. Czesław Miłosz: neviltis ir malonè ['Cz. Miłosz: desesperación y gracia']. - Tekstai apie tekstus ['Textos sobre textos']. Chicago: Algimanto Mackaus leidykla, 145-153.

Venclova, T. 1972b. Pradžios mitas ['El mito del inicio']. - Tekstai apie tekstus ['Textos sobre textos']. Chicago: Algimanto Mackaus leidykla, 25-33. 